\title{
Growth-promoting characteristics of potential nitrogen-fixing bacteria in the root of an invasive plant Ageratina adenophora
}

\author{
Kai Fang Equal first author, 1, 2, 3 , Zhu-Shou-Neng Bao ${ }^{\text {Equal first author, 1,3 }}$, Lin Chen ${ }^{1,2,3}$, Jie Zhou ${ }^{1,3}$, Zhi-Ping Yang ${ }^{1,3}$, Xing-Fan \\ Dong ${ }^{1,3}$, Han-Bo Zhang ${ }^{\text {Corresp. 1, 2,3 }}$ \\ ${ }^{1}$ State Key Laboratory for Conservation and Utilization of Bio-Resources in Yunnan, Yunnan University, Kunming, Yunnan Province, China \\ 2 School of Ecology and Environmental Science, Yunnan University, Kunming, Yunnan Province, China \\ 3 School of Life Sciences, Yunnan University, Kunming, Yunnan Province, China \\ Corresponding Author: Han-Bo Zhang \\ Email address: zhhb@ynu.edu.cn
}

Root endophytic nitrogen-fixing bacteria (reNFB) have been proposed as important contributors to the invasiveness of exotic legumes; however, the reNFB of invasive nonlegumes has received less attention. In particular, the growth-promoting effect of reNFB on invasive plants remains unknown. In this study, 131 strains of potential nitrogenfixing bacteria were isolated and purified from the roots of invasive plant, Ageratina adenophora, in Southwest China. Phylogenetically, these reNFB were categorized into three phyla at $97 \%$ sequence identity that included Proteobacteria (92.4\%), Actinobacteria $(4.6 \%)$ and Firmicutes (3.1\%). The dominant isolates ranked by number were Pseudomonas (80 isolates, 61.1\%), Rhizobium (12 isolates, 9.2\%) and Duganella (11 isolates, $8.4 \%)$. The community composition and diversity of $A$. adenophora reNFB were markedly different across study regions. The capacity of these reNFB to accumulate indolyl-3-acetic acid (IAA), solubilize phosphate, and produce siderophores was determined. All 131 isolates of reNFB accumulated IAA, 67 isolates solubilized phosphate and 108 isolates produced siderophores. Among the three dominant genera of reNFB, Pseudomonas had the highest phosphorus solubilization and siderophore production, while the accumulation of IAA in the genus Duganella was the lowest. Interestingly, the calculated reNFB Shannon diversity index of each $A$. adenophora individual was negatively correlated with the capacity of reNFB to produce growth-promoting products. Six randomly selected isolates from three dominant genera were further used to conduct inoculation experiments, and all isolates showed significant positive growth-promoting effects on $A$. adenophora seedlings. The contribution of reNFB to the root biomass was higher than that to the shoot biomass. Our results suggest that reNFB, similar to soil or nodular nitrogenfixing bacteria, can potentially promote plant growth and may play an important role in the invasion of nonleguminous plants. More detailed studies on the correlation between reNFB 
and invasive plants are necessary. 
1 Growth-promoting characteristics of potential

2 nitrogen-fixing bacteria in the root of an invasive plant

3 Ageratina adenophora

4

5 Kai Fang ${ }^{123 \dagger}$, Zhu-Shou-Neng Bao ${ }^{13 \dagger}$, Lin Chen ${ }^{123}$, Jie Zhou ${ }^{13}$, Zhi-Ping Yang ${ }^{13}$, Xing-Fan

6 Dong ${ }^{13}$, Han-Bo Zhang ${ }^{123}$

7

$8{ }^{1}$ State Key Laboratory for Conservation and Utilization of Bio-Resources in Yunnan, Yunnan

9 University, Kunming, Yunnan, China

$10{ }^{2}$ School of Ecology and Environmental Science, Yunnan University, Kunming, Yunnan, China

$11{ }^{3}$ School of Life Sciences, Yunnan University, Kunming, Yunnan, China

12 
Abstract

Root endophytic nitrogen-fixing bacteria (reNFB) have been proposed as important contributors to the invasiveness of exotic legumes; however, the reNFB of invasive nonlegumes has received less attention. In particular, the growth-promoting effect of reNFB on invasive plants remains unknown. In this study, 131 strains of potential nitrogen-fixing bacteria were isolated and purified from the roots of invasive plant, Ageratina adenophora, in Southwest China. Phylogenetically, these reNFB were categorized into three phyla at $97 \%$ sequence identity that included Proteobacteria (92.4\%), Actinobacteria (4.6\%) and Firmicutes (3.1\%). The dominant isolates ranked by number were Pseudomonas (80 isolates, 61.1\%), Rhizobium (12 isolates, 9.2\%) and Duganella (11 isolates, 8.4\%). The community composition and diversity of $A$. adenophora reNFB were markedly different across study regions. The capacity of these reNFB to accumulate indolyl-3-acetic acid (IAA), solubilize phosphate, and produce siderophores was determined. All 131 isolates of reNFB accumulated IAA, 67 isolates solubilized phosphate and 108 isolates produced siderophores. Among the three dominant genera of reNFB, Pseudomonas had the highest phosphorus solubilization and siderophore production, while the accumulation of IAA in the genus Duganella was the lowest. Interestingly, the calculated reNFB Shannon diversity index of each $A$. adenophora individual was negatively correlated with the capacity of reNFB to produce growth-promoting products. Six randomly selected isolates from three dominant genera were further used to conduct inoculation experiments, and all isolates showed significant positive growth-promoting effects on A. adenophora seedlings. The contribution of reNFB to the root biomass was higher than that to the shoot biomass. Our results suggest that reNFB, similar to soil or nodular nitrogen-fixing bacteria, can potentially promote plant growth and may play an important role in the invasion of nonleguminous plants. More detailed studies on the correlation between reNFB and invasive plants are necessary. 


\section{Introduction}

Ongoing globalization and climate warming have enhanced the migration of species (Lehan et al., 2013; Walther et al., 2002) and therefore have exacerbated the colonization of invasive plants in new habitats (Moles et al., 2008). Invasive plants that thrive in new environments have been reported to inhibit local plants from competing for more living resources through allelopathy (Bais et al., 2003) and other mechanisms (Hierro et al., 2005). Moreover, the invaded ecosystems tend to have higher net primary production (NPP) compared to native ecosystems (Wilsey and Polley, 2006), indicating that the growth requirements of invasive plants have a high environmental capacity. Invasive plants promote the development of their own communities through highly efficient nutrient cycling (Ehrenfeld, 2003). Liao et al. (2008) reviewed that the pools of carbon and nitrogen in the invaded systems were significantly increased. Thus, nutrient improvement can be proposed as an important contributor to the success of invaders over native flora. Previously, increased nitrogen input was well documented to facilitate the invasion of invasive plants (Brooks, 2003).

Recent studies have indicated that the newly established relationship between hosts and local microbes have greatly impacted the competitiveness of invasive plants (Van der Putten et al., 2007). For example, it has been suggested that invasive plants maintain long-term dominance by accumulating local pathogens (Eppinga et al., 2006) or beneficial microbes (Rout and Callaway, 2009; Van der Putten et al., 2013). Most invasive plants can form mutualistic relationships with local microbes, of which symbiotic nitrogen-fixing bacteria (NFB) play an extremely important role in gaining additional nutritional resources for invasive plants that are competing with native plants (Rodríguez-Echeverría and Traveset, 2015). Currently, the associations between reNFB and invasive legumes are widely studied. For example, Lafay and Burdon (2006) showed that the invasive leguminous plant Cytisus scoparius in Australia was able to form nodules with Bradyrhizobium, Rhizobium and Mesorhizobium. Parker et al. (2006) further demonstrated that the biomass of Cytisus scoparius when inoculated with Bradyrhizobium was twice that of a noninoculated plant. Wei et al. (2009) also demonstrated that Robinia pseudoacacia, a leguminous plant from North America, could invade China's barren regions by forming nodules with bacteria in local soils.

However, in addition to the root nodules of legumes, a variety of nitrogen-fixing bacteria have been isolated in the roots, stems and leaves of nonlegumes, which are named endophytic 
101

102

103

104

105

106

107

108

109

110

111

112

113

114

115

116

117

118

119

120

121

122

123

124

125

126

127

128

129

130

131

132

133

134

135

diazotrophs (Olivares et al., 1996). These endophytic diazotrophs have been reported as an important mechanism in facilitating the invasion of the exotic plant Sorghum halepense in grasslands where nitrogen sources are extremely scarce (Rout and Chrzanowski, 2009). In addition to nitrogen fixation, endophytic diazotrophs have also been shown to promote plant growth with their secondary metabolites (Carvalho et al., 2016), including indolyl-3-acetic acid (IAA) accumulation, phosphorus solubilization and siderophore production (Chauhan et al., 2013; Rout et al., 2013). Therefore, studies on the relationship between endophytic diazotrophs and invasive plants are important for better understanding the mechanisms underlying the colonization and dominance of invasive plants in nonnative habitats. Unfortunately, thus far, little is known about endophytic diazotroph communities of invasive nonlegumes in a relatively large introduced geographic range or their effects on promoting the growth of invasive plant seedlings.

Ageratina adenophora (Sprengel) R. M. King and H. Robinson is a perennial herb of the Compositae family that is native to Central America but a noxious weed in Asia, Africa, Oceania and Hawaii. It first invaded Yunnan Province, China, in the 1940s and is now widely distributed in Yunnan, Guizhou, Sichuan, Guangxi and Tibet provinces in Southwest China and has continuously spread east- and northward at a rate of approximately $20 \mathrm{~km}$ per year (Wang and Wang, 2006). A. adenophora has shown a strong acclimation capacity to a wide range of nitrogen environments (Wang and Feng, 2005), and its competitive ability could be promoted by artificially applying nitrogen (Zhao et al., 2007). Furthermore, Niu et al. (2007) showed that available soil nutrients (N, P and $\mathrm{K}$ ) were greatly increased in soils that were heavily invaded by A. adenophora. Xu et al. (2012) demonstrated that, compared to noninvaded habitats, $A$. adenophora accumulated more abundant and diverse nitrogen-fixing bacteria inhabiting rhizosphere soils in heavily invaded areas, suggesting a potential role of the nitrogen cycle, which is driven by bacteria, in the invasiveness of A. adenophora. However, no study has been conducted on the investigation of endophytic diazotrophs of $A$. adenophora, as well as their effects on promoting the growth performance of seedlings.

In this study, we first isolated endophytic diazotrophs of A. adenophora roots, named potential root endophytic nitrogen-fixing bacteria (reNFB), in a large geographic range and attempted to explore the community composition and phylogeny of $A$. adenophora reNFB from different regions. Second, we detected the growth-promoting products of all obtained reNFB, including IAA accumulation, phosphorus solubilization and siderophore production, and analyzed the differences in the ability of dominant reNFB to produce growth-promoting products. Finally, we carried out an inoculation experiment with the focal isolates to verify the growthpromoting effects of reNFB on the seedlings of $A$. adenophora. 


\section{Materials and methods}

137

138

\subsection{Isolation and identification of reNFB}

\subsubsection{Root collection}

We collected A. adenophora roots from 5 regions in Yunnan Province $\left(22^{\circ} 37^{\prime}-25^{\circ} 52^{\prime} \mathrm{N}\right.$, $99^{\circ} 18^{\prime}-104^{\circ} 10^{\prime} \mathrm{E}, 1708-2128 \mathrm{~m}$ ), Southwest China, and named them XM, CY, XS, WS and YL (Table 1). All of the sampling sites were along roadsides and had been badly invaded by $A$. adenophora with coverage of more than $80 \%$ (visually estimated). In August 2016, three mature and healthy $A$. adenophora were selected in each region, and the whole plant was dug up with a shovel and then brought back to the laboratory together with its rhizosphere soils. The roots were used to isolate endophytic bacteria within 3 days after collection.

\subsubsection{Bacterial isolation and molecular identification}

We cut 10 randomly selected fine-root fragments from each harvested $A$. adenophora individual, rinsed them with tap water in empty petri plates and surface sterilized them as follows: fine roots were submerged in 95\% ethanol for $10 \mathrm{~s}$ and $5 \%$ sodium hypochlorite for $3 \mathrm{~min}$ and were rinsed with sterile water 3 to 5 times, and then the surface water of the roots was dried with sterile filter paper. Roots were printed on nutrient agar (NA) culture medium (1000 ml distilled water containing beef extract $1 \mathrm{~g}$, peptone $5 \mathrm{~g}$, yeast extract $2 \mathrm{~g}, \mathrm{NaCl} 5 \mathrm{~g}$, and agar $15 \mathrm{~g}$, pH 6.8 - 7.0) to confirm that the surface sterilization was successful. Then, the disinfected fine roots were cut into fragments of approximately $0.5 \mathrm{~cm}$ for detection of endophytic bacteria. In total, one hundred and fifty root fragments were subjected to testing. The thoroughly surface-sterilized root fragments were placed in separate centrifuge tubes containing $150 \mu \mathrm{l}$ of sterile water, crushed with a sterilized pipette tip, and streaked with inoculation tools onto modified yeastmannitol agar (YMA) culture medium (1000 ml distilled water containing D-mannitol $10.00 \mathrm{~g}$, yeast extract $3.00 \mathrm{~g}, \mathrm{MgSO}_{4} \cdot 7 \mathrm{H}_{2} \mathrm{O} 0.20 \mathrm{~g}, \mathrm{NaCl} 0.10 \mathrm{~g}, \mathrm{~K}_{2} \mathrm{HPO}_{4} 0.25 \mathrm{~g}, \mathrm{KH}_{2} \mathrm{PO}_{4} 0.25 \mathrm{~g}$, agar 15.00-18.00 g, and 4\% Congo red $1 \mathrm{ml}, \mathrm{pH} 6.8$ - 7.0) (Kanu and Dakora, 2012). The plates were sealed with parafilm and then cultured for 3-5 days at $28{ }^{\circ} \mathrm{C}$ to form colonies. The assay of each root fragment was repeated 3 times, and a total of 450 petri dishes were used to isolate endophytic bacteria of $A$. adenophora in this experiment. After 3 to 5 days of culture, a single colony with good growth and without Congo red absorption was selected for purification.

Numerous studies have shown that bacteria that can grow normally in medium lacking nitrogen have the potential to fix nitrogen (Ding et al., 2005; Park et al., 2005; Silva et al., 2011). In order to screen out the candidate bacteria with nitrogen fixation from the endogenous bacteria obtained by the above steps, the purified isolates were inoculated into nitrogen-free liquid medium (1000 ml distilled water containing $\mathrm{KH}_{2} \mathrm{PO}_{4} 0.2 \mathrm{~g}, \mathrm{MgSO}_{4} \cdot 7 \mathrm{H}_{2} \mathrm{O} 0.2 \mathrm{~g}, \mathrm{NaCl} 0.2 \mathrm{~g}$, $\mathrm{CaCO}_{3} 5.0 \mathrm{~g}, \mathrm{C}_{6} \mathrm{H}_{14} \mathrm{O}_{6} 10.0 \mathrm{~g}$, and $\mathrm{CaSO}_{4} \cdot 2 \mathrm{H}_{2} \mathrm{O} 0.1 \mathrm{~g}, \mathrm{pH} 7.0$ ) (Ashby, 1907) in a glass test tube 
171

172

173

174

175

176

177

178

179

180

181

182

183

184

185

186

187

188

189

190

191

192

193

194

195

196

197

198

199

200

201

202

203

204

205

206

207

covered with a plastic stopper to confirm their potential for nitrogen fixation, and the isolates capable of being continuously cultured for 7 generations with 24 hours per generation were preliminarily identified as nitrogen-fixing bacteria (Dataset S1) (Aeron et al., 2015).

The reNFB of $A$. adenophora selected from above were inoculated into test tubes containing $5 \mathrm{ml}$ yeast-mannitol (YM) liquid culture medium and cultured for 24 hours under the conditions of $28{ }^{\circ} \mathrm{C}$ and $180 \mathrm{r} / \mathrm{min}$. Then, $1 \mathrm{ml}$ of bacterial suspension was taken and centrifuged for $1 \mathrm{~min}$ at 12,000 rpm to obtain the bacterial precipitate. Total genomic DNA was extracted directly from the bacterial precipitate of each isolate using an AxyPrep Bacterial Genomic DNA Miniprep Kit. The primers 27F (5 - CGA AGT AGT TTG ATC CTG GCT - 3 ) and 1523R (5 - AGG AGG TGA TCC AGC CGC A - 3') were used to amplify approximately 1500 bp of 16S rRNA (Edwards et al., 1989). Each $50 \mu \mathrm{l}$ PCR included $5 \mu 10 \times$ amplification buffer, $5 \mu 1 \mathrm{dNTP}$ mixture $(2 \mathrm{mM}), 0.25 \mu \mathrm{l}$ Taq DNA polymerase $(2 \mathrm{U} / \mu \mathrm{l}), 1 \mu \mathrm{l}$ each primer $(10 \mu \mathrm{M}), 1 \mu \mathrm{l}$ template

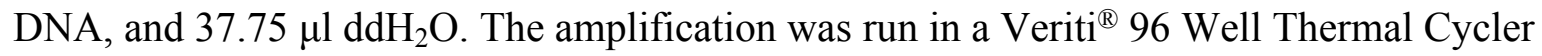
(Applied Biosystems Inc., Foster City, CA, USA) $\left(3 \mathrm{~min}\right.$ at $94{ }^{\circ} \mathrm{C}$, followed by 35 cycles of $30 \mathrm{~s}$ at $94{ }^{\circ} \mathrm{C}, 45 \mathrm{~s}$ at $54{ }^{\circ} \mathrm{C}$, and $100 \mathrm{~s}$ at $72{ }^{\circ} \mathrm{C}$, and $7 \mathrm{~min}$ at $72{ }^{\circ} \mathrm{C}$ ). PCR products were tested by $1 \%$ gel electrophoresis and then sent to the Beijing Genomics Institute (BGI) for bidirectional sequencing.

We processed the raw sequence data with SeqMan software (DNAStar 7.1, Madison, WI, USA) to pair the merged bidirectional sequencing DNA, resulting in a single sequence with a length of approximately $1400 \mathrm{bp}$. Based on the GenBank database, we carefully conducted sequence homology analysis and sequence correction and then cut out chimeric bases using ClustalX 2.1 (Thompson et al., 1997). After that, we grouped the resulting sequences that were approximately $1300 \mathrm{bp}$ long into operational taxonomic units (OTUs) at a 97\% sequence identity with Mothur 1.35.1 (Dataset S1) (Schloss et al., 2009).

\subsubsection{Phylogenetic analysis}

We randomly selected representative isolates from each OTU, and the closest relatives of the representative isolates were searched and downloaded in the GenBank nr/nt database (2018.06) (Dataset S1). Phylogenetic trees were constructed with the sequences of both representative isolates and reference strains using MrBayes 3.2.5 (Huelsenbeck and Ronquist, 2001) and raxmlGUI 1.5b1 (Silvestro and Michalak, 2012). Bayesian analysis was performed in 2 million operations with the model GTR $+\mathrm{T}+\mathrm{G}$ and parameters nst $=6$ and rates=gamma, which was calculated by the jModelTest 2.0 (Darriba et al., 2012; Guindon and Gascuel, 2003), and maximum likelihood was carried out in 1000 replicates through rapid bootstrap analysis. Phylogenetic trees were edited in FigTree v1.4.3 (Rambaut, 2016) and displayed by combining them into one figure with Adobe Illustrator CC 2015 (Adobe Systems Inc., San Jose, CA, USA). The nucleotide sequences reported in this study have been deposited in GenBank under accession numbers MK249666-MK249688 and MK574703 - MK574810. 
208

209

210

211

212

213

214

215

216

217

218

219

220

221

222

223

224

225

226

227

228

229

230

231

232

233

234

235

236

237

238

239

240

241

242

243

\subsection{Growth-promoting products of reNFB}

\subsubsection{IAA accumulation test}

Salkowski's reaction was used to test IAA accumulation of $A$. adenophora reNFB at 72 hours and 144 hours of culture, respectively (Loper and Schroth, 1986). The suspension was prepared by culturing bacteria in YM liquid medium at $28^{\circ} \mathrm{C}$ and $180 \mathrm{r} / \mathrm{min}$ for 24 hours. Then, $5 \mu$ of bacterial suspension was inoculated into $5 \mathrm{ml}$ of liquid King's B medium ( $5 \mathrm{ml}$ glycerine containing peptone $20.0 \mathrm{~g}, \mathrm{~K}_{2} \mathrm{HPO}_{4} 1.5 \mathrm{~g}$, and $\mathrm{MgSO}_{4} \cdot 7 \mathrm{H}_{2} \mathrm{O} 1.5 \mathrm{~g}, \mathrm{pH} 7.2 \pm 0.2$ ) containing L$\operatorname{TRP}(0.5 \mathrm{~g} / \mathrm{ml})$, which were incubated at $28^{\circ} \mathrm{C}$ and $180 \mathrm{r} / \mathrm{min}$ for 72 hours and 144 hours, respectively. After that, bacteria cells were removed by centrifugation for $5 \mathrm{~min}$ at 12,000 rpm, and $500 \mu \mathrm{l}$ supernatant and $500 \mu \mathrm{l}$ Salkowski reagent (ferric chloride $12 \mathrm{~g}$, concentrated sulfuric acid $430 \mathrm{ml}$, and deionized water $570 \mathrm{ml}$ ) were mixed and allowed to react for $30 \mathrm{~min}$ in the dark prior to the absorbance value being measured at $530 \mathrm{~nm}$ in a SpectraMax ${ }^{\circledR} 340 \mathrm{PC}^{384}$ (Molecular Devices Inc., Silicon Valley, CA, USA). King's B medium that was not inoculated was used as a reference instead of supernatant. The assay was repeated 3 times for each isolate. After subtracting the reference absorbance values from the sample, the IAA content of each isolate was calculated using the regression curve of the IAA standard (Dataset S1).

2.2.2 Phosphate solubility test

Phosphate solubility was determined by measuring the diameters of the transparent circle formed by dissolution of phosphate on glucose yeast (GY) medium (1000 ml distilled water containing glucose $10 \mathrm{~g}$, yeast powder $2 \mathrm{~g}$, and agar $15 \mathrm{~g}$, pH 7.0) containing $\mathrm{K}_{2} \mathrm{HPO}_{4}(50 \mathrm{ml}$ distilled water containing $\left.\mathrm{K}_{2} \mathrm{HPO}_{4} 5 \mathrm{~g}\right)$ and $\mathrm{CaCl}_{2}\left(100 \mathrm{ml}\right.$ distilled water containing $\left.\mathrm{CaCl}_{2} 10 \mathrm{~g}\right)$ (Sylvester-Bradley et al., 1982). Five microliters of bacterial suspension, which was activated by YM liquid medium, was inoculated into $5 \mathrm{ml}$ of liquid King's B culture medium for 48 hours at $28^{\circ} \mathrm{C}$ and $180 \mathrm{r} / \mathrm{min}$, and then $5 \mu \mathrm{l}$ of King's B culture with bacteria was inoculated onto the GY test plate. Sterile water was used as a control instead of a bacterial suspension. The assay was repeated 4 times for each isolate. The ratio of the transparent circle diameter to the colony diameter indicated the phosphate solubility index of each isolate, and solubility indices equal to 1 were considered negative (Dataset S1).

\subsubsection{Siderophore production test}

A chrome azurol S (CAS) liquid assay was used to test siderophore production (Machuca and Milagres, 2003). The $100 \mu \mathrm{CAS}$ assay solution, prepared according to Schwyn and Neilands (1987), was injected into the $100 \mu$ centrifugal supernatant of King's B bacterial culture (as mentioned in the IAA accumulation test), which reacted for $60 \mathrm{~min}$ at room temperature, and then the absorbance value was measured at $630 \mathrm{~nm}$ in a SpectraMax ${ }^{\circledR} 340 \mathrm{PC}^{384}$ (Molecular Devices Inc., Silicon Valley, CA, USA). Liquid King's B medium was used as a reference instead of supernatant. The assay was repeated 3 times for each isolate. Siderophore 
244

245

246

247

248

249

250

251

252

253

254

255

256

257

258

259

260

261

262

263

264

265

266

267

268

269

270

271

272

273

274

275

276

277

278

279

280

units were calculated by (Ar - As) / Ar, where Ar and As represent the absorbance values of the reference and sample, respectively, and percentages of siderophore units less than $10 \%$ were considered negative (Machuca and Milagres, 2003) (Dataset S1).

\subsection{Growth-promoting effects of reNFB}

According to phylogenetic analysis, 6 isolates were randomly selected from 3 dominant genera to study their effects on the growth of A. adenophora seedlings, including 2 Pseudomonas (WS29 and WS14), 3 Rhizobium (XM06, XM04 and WS05) and 1 Duganella (XS01). Seeds and soil were respectively collected from wild A. adenophora and cropland in Kunming city, Yunnan Province, Southwest China. Seeds were surface sterilized by submerging them in $4 \%$ sodium hypochlorite for $5 \mathrm{~min}$ and were rinsed with sterile water 5 to 6 times. Substrate that included cropland soils, humus, and vermiculite were mixed at a proportion of 3:2:1 and sterilized 3 times at 24 hour intervals by autoclaving $\left(121^{\circ} \mathrm{C}, 0.135 \mathrm{MPa}, 2\right.$ hours $)$. Five milliliters of bacterial suspension $\left(10^{9} \mathrm{CFU} / \mathrm{ml}\right)$ of each isolate mixed with $50 \mathrm{ml}$ of sterile water was separately injected into a sterilized plastic cup $(700 \mathrm{ml})$ containing $20 \mathrm{~g}$ sterilized soil mixture and sown with approximately 30 surface-sterilized seeds of $A$. adenophora in each cup, and the cup was sealed with sterilized PTFE bacteria filter membranes. The assay was repeated 3 times for each isolate, and the control group was not inoculated with bacterial suspension. Seeds were germinated in an RXZ-380D growth chamber (Ningbo Southeast instrument Co., Ltd, Ningbo, China) with a temperature of $25 / 20^{\circ} \mathrm{C}$ (day/night), light intensity of 12000 lux for a 12 hour photoperiod and humidity of $60 \%$.

After 40 days, seedlings were thinned out of each cup, and only one seedling with the best growth was kept, and the remaining seedlings were harvested on the 60th day of continuous growth. The surface soil of harvested seedlings was removed with an SB3200 ultrasonic instrument (Branson Ultrasonics Co., Ltd, Shanghai, China), and the surface water was dried with filter paper. After that, the length and wet biomass of shoots and roots were measured, and their dry biomass was measured after drying at $60{ }^{\circ} \mathrm{C}$ for 48 hours (Dataset $\mathrm{S} 1$ ).

\subsection{Statistical analyses}

R 3.5.2 was used for random sampling among all isolates, and the OTU rarefaction curve at 97\% sequence identity was plotted in Excel 2013 (Microsoft Inc., Redmond, WA, USA). The Shannon diversity index of each A. adenophora individual was calculated using Excel 2013 (Microsoft Inc., Redmond, WA, USA) as previously described (Hill et al., 2003). One-way ANOVA was used to compare Shannon diversity across different study regions. A nonparametric test was used to compare the production capacity of growth-promoting products between sampling areas. To meet the normality assumption, log transformations were applied to IAA accumulation and the phosphorus solubility index, and a square-root transformation was applied to siderophore units. One-way ANOVA was used to calculate these three kinds of growth-promoting products produced by A. adenophora reNFB across the dominant genus, and 
281 the homogeneity test of variance passed or failed to select Duncan or Dunnett T3 for pairwise

282

283

284

285

286

287

288

289

290

291

292

293

294

295

296

297

298

299

300

301

302

303

304

305

306

307

308

309

310

311

312

313

314

315

comparison. In addition, we performed linear regression analysis between the Shannon diversity index of each $A$. adenophora and their reNFB growth-promoting product productivity.

Log transformations were applied to the root and shoot biomass of the experimental seedlings to meet normality and homoscedasticity assumptions. Independent-samples $\mathrm{T}$ test was used to compare the different effects of each bacterial treatment and sterilized control on the growth performance of $A$. adenophora seedlings. In addition, we calculated the response index (RI) to evaluate the effect of reNFB on the shoots and roots of $A$. adenophora seedlings. RI was calculated as follows: $\left(\right.$ variable $_{\text {inoculation }}$ - variable sterility $_{\text {) }}$ variable $_{\text {sterility }}$ (Williamson and Richardson, 1988), where variable inoculation $_{\text {and }}$ variable $_{\text {sterility }}$ were the shoot or root length and biomass of each cup (replicates), with inoculation treatment and sterilized control, respectively. Normality assumptions were not met; thus, nonparametric tests were used to compare the differences in RI between shoots and roots.

In addition to the calculation of Shannon diversity, all other statistical analyses were conducted by using SPSS 22.0 (SPSS Inc., Chicago, IL, USA). In addition to the OTU rarefaction curve, all other figures were created using GraphPad Prism 7 (GraphPad Software Inc., San Diego, CA, USA).

\section{Results}

\subsection{Species composition of reNFB}

In total, 150 isolates were obtained from the roots of $15 \mathrm{~A}$. adenophora individuals across the 5 regions mentioned above by using YMA selective medium, but only 131 isolates were able to grow continuously for 7 culture generations in nitrogen-free medium, including 29 isolates from XM, 24 from CY, 23 from XS, 27 from WS and 28 from YL. In the phylogenetic tree (Fig. 1 ), these isolates were placed into three phyla at $97 \%$ sequence identity and included Proteobacteria (92.4\%), Actinobacteria (4.6\%) and Firmicutes (3.1\%). All isolates in Proteobacteria were further divided into three subgroups, including alpha (18.2\%), beta (14.1\%), and gamma (67.8\%). At the genus level, the dominant isolates were Pseudomonas (80 isolates, 61.1\%), followed by Rhizobium (12 isolates, 9.2\%) and Duganella (11 isolates, 8.4\%). Other genera had an occurrence frequency of less than $3.0 \%$.

At the genus level, there were clear differences in the composition of $A$. adenophora reNFB among the study regions (Fig. 2A). WS contained the most abundant isolates (11 genera), while YL had the least abundant isolates ( 3 genera). With the exception of XS, in which Duganella (39.1\%) was the most abundant reNFB, Pseudomonas was the most dominant reNFB in the other 4 regions, accounting for $65.5 \%$ in XM, $83.3 \%$ in $\mathrm{CY}, 44.4 \%$ in WS, and $89.3 \%$ in YL. The Shannon diversity index calculated at $97 \%$ of the identity level showed that the diversity of XS 
316

317

318

319

320

321

322

323

324

325

326

327

328

329

330

331

332

333

334

335

336

337

338

339

340

341

342

343

344

345

346

347

348

349

350

and WS were significantly higher than that of CY, XM and YL (Fig. 2B).

\subsection{Growth-promoting products of reNFB}

Of the 131 reNFB isolated in this experiment, 66 isolates were able to simultaneously accumulate IAA, dissolve phosphate and produce siderophores, including 57 Pseudomonas sp., 3 Rhizobium sp., 1 Duganella sp., 1 Agrobacterium sp., 1 Nocardioides sp., 1 Variovorax sp., 1 Pseudarthrobacter sp. and 1 Paenibacillus sp.. All 131 reNFB could accumulate IAA, and the content of IAA in most isolates gradually increased with increasing incubation time. For example, the number of isolates with a yield of IAA greater than $10 \mu \mathrm{g} / \mathrm{ml}$ increased from 19 isolates with an incubation time of 72 hours to 29 isolates with an incubation time of 144 hours (Fig. 3A, 3B). Sixty-seven isolates of reNFB were able to dissolve phosphate, accounting for $51.15 \%$ of the total isolates, mainly distributed in XM, CY and YL (Fig. 3C). There were 108 isolates that could produce siderophores (siderophore units greater than $10 \%$ ), but only 10 isolates in XS could produce siderophores (Fig. 3D). In addition, the ability of Pseudomonas to dissolve phosphate and to produce siderophores was relatively high among the three dominant genera (Fig. 3G, Fig. 3H), while the accumulation of IAA in the genus Duganella was the lowest among the three dominant genera (Fig. 3E, 3F). Interestingly, the calculated reNFB Shannon diversity index of each $A$. adenophora individual was negatively correlated with the capacity of reNFB to produce growth-promoting products, and all were statistically significant, with the exception of IAA at 144 hours (Fig. 4).

\subsection{Effects of reNFB on the growth of $A$. adenophora seedlings}

Root endophytic nitrogen-fixing bacteria differed in their effects on the growth performance of $A$. adenophora seedlings (Fig. 5). The average shoot length of $A$. adenophora seedlings treated with Duganella sp. (OTU02; XS01) was lower than that of the control group, all others revealed positive effects on various plant growth metrics. The WS05 isolate (Rhizobium sp.) was the best growth-promoting isolate of $A$. adenophora among these six reNFB, which greatly increased the length of shoots $(P<0.001)$ and roots $(P<0.001)$ and had an evident positive effect on shoot biomass $\left(P_{\text {wet }}<0.001 ; P_{\text {dry }}<0.001\right)$ and root biomass $\left(P_{\text {wet }}=0.004 ; P_{\text {dry }}=0.005\right)$.

Compared to the shoots, the six selected isolates showed a stronger positive effect on the roots of seedlings, and the wet- and dry-biomass RI of roots were significantly higher than that of shoots (Fig. 6).

\section{Discussion}

Exotic plants are able to change soil nitrogen cycling in an invaded range (Rout and Callaway, 2009), and the increase in available soil nitrogen can improve the competitiveness of invasive plants (Liao et al., 2008). These facts undoubtedly imply that the abundance and diversity of nitrogen-fixing bacteria may be important factors for plant invasion (Rodríguez- 
351

352

353

354

355

356

357

358

359

360

361

362

363

364

365

366

367

368

369

370

371

372

373

374

375

376

377

378

379

380

381

382

383

384

385

386

Echeverría et al., 2007). Until now, many efforts have focused on nitrogen-fixing bacteria of invasive legumes (Lafay and Burdon, 2006; Parker et al., 2006); however, the characterization of nitrogen-fixing bacteria in invasive non-legumes has been limited. In this study, 150 endophytic bacteria were initially isolated from roots of invasive A. adenophora by using modified YMA culture medium, and 131 isolates were preliminary determined as reNFB by continuous culture for 7 generations in nitrogen-free culture medium (Aeron et al., 2015). The dominant reNFB of $A$. adenophora was Pseudomonas (61.1\%), Rhizobium (9.2\%) and Duganella (8.4\%) (Fig. 1). Pseudomonas and Rhizobium have been widely reported as endogenous NFB of nonlegumes (Carvalho et al., 2016; Santi et al., 2013). For example, nitrogen-fixing Pseudomonas sp. have been isolated from stem and leaf tissues of sugarcane (Magnani et al., 2010), barley seeds (Zawoznik et al., 2014) and wild rice roots (Chaudhary et al., 2012). In particular, Pseudomonas accounted for $61.1 \%$ of the reNFB of $A$. adenophora, suggesting a possible important contribution of Pseudomonas to A. adenophora competitiveness. Rhizobium are mainly reported as NFB of legumes (Lafay and Burdon, 2006), in nonlegumes, e.g., Biswas et al. (2000) demonstrated that Rhizobium could infect rice and increase rice yield. The genus Duganella was first proposed by Hiraishi et al. (1997) as a reclassification of a misnamed strain, and until now, its interaction with plants has not been clear. Li et al. (2004) isolated Duganella violaceinigra sp. from a forest soil sample collected from Yunnan Province, Southwest China. In this study, Duganella were isolated as reNFB, indicating that soil-dwelling Duganella can infect $A$. adenophora and may make an important contribution to A. adenophora invasiveness. In addition, compared to another study of nonsymbiotic NFB inhabiting rhizosphere soils of $A$. adenophora in Yunnan Province (Xu et al., 2012), Pseudomonas and Rhizobium accounted for only 8.2\% and $7.0 \%$, it can be concluded that there are differences between reNFB and nonsymbiotic NFB of $A$. adenophora. Therefore, there might be host specialization in the interaction between $A$. adenophora and reNFB. Although plants can dramatically modify their soil environment to shape the soil microbial communities through the rhizosphere effect (Bremer et al., 2009; Jones et al., 2009) and improve themselves growth performance, the selective accumulation of specific reNFB, e.g., Pseudomonas, may be an effective strategy for the growth advantage of $A$. adenophora.

It was previously reported that the endogenous bacteria of the same plant species revealed regional endemism ( $\mathrm{Li}$ et al., 2012), and we also found that there were marked differences in the community composition and diversity of A. adenophora reNFB in different regions (Fig. 2). However, the regions in this paper were distributed in a relatively large geographic range, and there were certain differences in environmental background, which might explain the differences in reNFB of A. adenophora. However, differences in reNFB diversity might be related to plant growth stage. It was reported that the diversity of functional endogenous bacteria was distinct in

PeerJ reviewing PDF | (2018:12:33237:2:0:NEW 24 Apr 2019) 
387

388

389

390

391

392

393

394

395

396

397

398

399

400

401

402

403

404

405

406

407

408

409

410

411

412

413

414

415

416

417

418

419

420

421

422

different stages of plant growth (Loaces et al., 2011). The five regions were distributed in three latitudes, where $A$. adenophora might be in different development stages under certain light and temperature conditions when we sampled in August.

Previous studies have shown that plant endogenous bacteria are able to not only fix nitrogen but also accumulate IAA (Chauhan et al., 2013), dissolve phosphate (Kuklinsky-Sobral et al., 2004) and produce siderophores (Loaces et al., 2011). We measured 131 isolates of $A$. adenophora reNFB and found that all isolates accumulated IAA (Fig. 3A, Fig. 3B), 67 isolates solubilized phosphorous (Fig. 3C) and 108 isolates produced siderophores (Fig. 3D). Among the three dominant genera, Pseudomonas showed the highest growth-promoting product productivity (Fig. 3E to Fig. 3H). Previously, Pseudomonas were reported as excellent producers of various crop growth regulators that stimulate plant growth (Pastor et al., 2014) and inhibit pathogen infection (Khare and Arora, 2010). However, Chauhan et al. (2013) showed that the production capacity of growth-promoting products of Bacillus sp. isolated from sugarcane was higher than that of Pseudomonas sp. It is suggested that different Pseudomonas strains from different hosts vary in IAA-accumulation capacity. Moreover, all of these growth-promoting products were measured in vitro in this study and may be different in vivo because the specific functions of reNFB in living plants are also influenced by plant physiological and environmental pressures (Moseman et al., 2009).

Notably, the Shannon diversity index was negatively correlated with the productivity of all growth-promoting products, and all were statistically significant, with the exception of IAA in 144 hours (Fig. 4). Considering that the number of reNFB isolated from each A. adenophora was similar, we speculated that even though the microbes had functional redundancy (Miki et al., 2014), the infection of functional microbes to host plants still had a certain threshold limit, by which the deficiency of microbial functions for host growth had to be compensated by improving their diversity or vice versa, resulting in a trade-off between quantity and diversity of functional microbes assembled within plants. There is some evidence for this concept in a previous study, where Torres-Cortés et al. (2018) suggested that nutrient availability during germination elicited changes in the composition of microbial communities by potentially selecting microbial groups with functional traits linked to copiotrophy. Thus, it represents a compelling field for further investigation of the interaction between reNFB and $A$. adenophora in vivo.

In the inoculation experiment, we verified the positive effect of reNFB on the seedlings of $A$. adenophora (Fig. 5). The isolate WS05 (Rhizobium sp.) revealed the best growth-promoting effect, while its IAA accumulation, phosphorus solubilization and siderophore production was relatively low among the 6 inoculated isolates. The results indicated that the growth-promoting products of reNFB were not the crucial factors influencing seedling growth of $A$. adenophora in the conditions of this experiment. However, the diversified NFB may differ from one another in 
423

424

425

426

427

428

429

430

431

432

433

434

435

436

437

438

439

440

441

442

443

444

445

446

447

448

449

450

451

452

453

454

455

456

457

458

459

460

terms of the other functions they perform within an ecosystem, and the changes in habitat conditions may also lead to changes in the main mechanism of microbial effects. For example, Moseman et al. (2009) indicated that NFB showed various physiological and ecological functions in three wetland invasion systems. There is no doubt that the invasive process of plants will encounter many unknown environments. At this time, the multifunctional characteristics of reNFB are particularly important. Moreover, the positive effect of reNFB on the roots of $A$. adenophora seedlings was stronger than that on the shoots (Fig. 6). The reason for this finding may be that most endogenous bacteria have tissue specificity (Lodewyckx et al., 2002), which means that reNFB likely produce various growth products to function preferentially in the roots.

In this study, the positive effect of endophytic nitrogen-fixing bacteria on $A$. adenophora growth was proposed. However, native plants also commonly harbor endogenous nitrogen-fixing bacteria with positive effects (Olivares et al., 1996). Thus, whether the endogenous nitrogenfixing bacteria enriched by invasive plants and native species are different, both in the species composition and in the growth-promoting of their hosts, must be further compared. A previous study on the competition of $A$. adenophora with native species in new habitats mainly involved its leaf litter allelopathy (Inderjit et al., 2011). Therefore, it would be interesting to determine whether the secondary metabolites of $A$. adenophora or soil type in the invaded sites influence the population dynamics of rhizosphere and endophytic nitrogen-fixing bacteria, which in turn enhance the growth advantage of $A$. adenophora. In addition, for each sampling region, only three plant individuals were collected, and nearly 30 bacteria were isolated in this study. Because the species rarefaction curve did not reach a plateau (Supplementary Fig. S1), it is expected that new OTUs will be discovered if more isolates are taken. Therefore, more strains should be isolated; particularly, new techniques such as high-throughput sequencing should be performed to indicate the reNFB diversity of A. adenophora in Yunnan Province. Physiological and morphological characteristics should also be taken into taxonomic classification of strains because solely using $16 \mathrm{~S}$ rRNA gene sequences is not reliable below genus level. More importantly, it is worth determining the nitrogenase activity capacity as well as the nifH gene diversity for these reNFB to establish the direct relationship between nitrogen-fixing bacteria and A. adenophora invasion.

\section{Conclusions}

In conclusion, there were a variety of endophytic NFB inhabiting the roots of $A$. adenophora, and the dominant genera ranked by number were Pseudomonas, Rhizobium and Duganella. The number of reNFB was similar across different geographical regions, but the composition and diversity were markedly different. In addition to nitrogen fixation, the reNFB also distinctly accumulated IAA, dissolved phosphate and produced siderophores. Furthermore, plants with high reNFB diversity generally had low growth-promoting product productivity. The inoculation experiment verified that reNFB had a significant positive effect on the growth of $A$. 
461

462

463

464

465

adenophora seedlings, particularly on root growth. It is necessary to carry out further studies on the response of $A$. adenophora to reNFB under various environmental conditions.

\section{Acknowledgements}

Authors thank Huan Yang, Yi-Shan Chen, Yi-Fang Miao, Tian Zeng and Wen-Ti Zheng at Yunnan University, for partially sampling in wild and experiment performance.

\section{References}

Aeron, A., Chauhan, P.S., Dubey, R.C., Maheshwari, D.K., Bajpai, V.K., 2015. Root nodule bacteria from Clitoria ternatea $\mathrm{L}$. are putative invasive non-rhizobial endophytes. Can. J. Microbiol. 61, 131-142. DOI: 10.1139/cjm-2014-0483.

Ashby, S.F., 1907. Some observations on the assimilation of atmospheric nitrogen by a free living soil organism, Azotobacter chroococcum of Beijerinck. J. Agric. Sci. 2, 35-51. DOI:10.1017/S0021859600000988.

Bais, H.P., Vepachedu, R., Gilroy, S., Callaway, R.M., Vivanco, J.M., 2003. Allelopathy and exotic plant invasion: From molecules and genes to species interactions. Science 301, 13771380. DOI:10.1126/science.1083245.

Biswas, J.C., Ladha, J.K., Dazzo, F.B., 2000. Rhizobia inoculation improves nutrient uptake and growth of lowland rice. Soil Sci. Soc. Am. J. 64, 1644-1650.

DOI:10.2136/sssaj2000.6451644x.

Bremer, C., Braker, G., Matthies, D., Beierkuhnlein, C., Conrad, R., 2009. Plant presence and species combination, but not diversity, influence denitrifier activity and the composition of nirK-type denitrifier communities in grassland soil. FEMS Microbiol. Ecol. 70, 377-387. DOI:10.1111/j.1574-6941.2009.00732.x.

Brooks, M.L., 2003. Effects of increased soil nitrogen on the dominance of alien annual plants in the Mojave Desert. J. Appl. Ecol. 40, 344-353. DOI:10.1046/j.1365-2664.2003.00789.x.

Carvalho, T.L.G., Ballesteros, H.G.F., Thiebaut, F., Ferreira, P.C.G., Hemerly, A.S., 2016. Nice to meet you: genetic, epigenetic and metabolic controls of plant perception of beneficial associative and endophytic diazotrophic bacteria in non-leguminous plants. Plant Mol. Biol. 90, 561-574. DOI:10.1007/s11103-016-0435-1.

Chaudhary, H.J., Peng, G., Hu, M., He, Y., Yang, L., Luo, Y., Tan, Z., 2012. Genetic diversity of endophytic diazotrophs of the wild rice, Oryza alta and identification of the new diazotroph, Acinetobacter oryzae sp. nov. Microb. Ecol. 63, 813-821. DOI:10.1007/s00248-011-9978-5.

Chauhan, H., Bagyaraj, D.J., Sharma, A., 2013. Plant growth-promoting bacterial endophytes 
495

496

497

498

499

500

501

502

503

504

505

506

507

508

509

510

511

512

513

514

515

516

517

518

519

520

521

522

523

524

525

526

527

528

529

530

from sugarcane and their potential in promoting growth of the host under field conditions. Exp. Agric. 49, 43-52. DOI:10.1017/S0014479712001019.

Darriba, D., Taboada, G.L., Doallo, R., Posada, D., 2012. JModelTest 2: more models, new heuristics and parallel computing. Nat. Methods 9, 772. DOI:10.1038/nmeth.2109.

Ding, Y., Wang, J., Liu, Y., Chen, S., 2005. Isolation and identification of nitrogen-fixing bacilli from plant rhizospheres in Beijing region. J. Appl. Microbiol. 99, 1271-1281. DOI:10.1111/j.1365-2672.2005.02738.x.

Edwards, U., Rogall, T., Blöcker H., Emde, M., Böttger E.C., 1989. Isolation and direct complete nucleotide determination of entire genes. Characterization of a gene coding for 16s ribosomal RNA. Nucleic Acids Res 17, 7843-7853. DOI: 10.1093/nar/17.19.7843.

Ehrenfeld, J.G., 2003. Effects of exotic plant invasions on soil nutrient cycling processes. Ecosystems 6, 503-523. DOI:10.1007/s10021-002-0151-3.

Eppinga, M.B., Rietkerk, M., Dekker, S.C., Ruiter, P.C. De, 2006. Accumulation of local pathogens: a new hypothesis to explain exotic plant invasions. Oikos 114, 168-176. DOI:10.1111/j.2006.0030-1299.14625.x.

Guindon, S., Gascuel, O., 2003. A simple, fast, and accurate algorithm to estimate large phylogenies by Maximum Likelihood. Syst. Biol. 52, 696-704. DOI:10.1080/10635150390235520

Hierro, J.L., Maron, J.L., Callaway, R.M., 2005. A biogeographical approach to plant invasions : the importance of studying exotics in their introduced and native range. J. Ecol. 93, 5-15. DOI:10.1111/j.1365-2745.2004.00953.x.

Hill, T.C.J., Walsh, K.A., Harris, J.A., Moffett, B.F., 2003. Using ecological diversity measures with bacterial communities. FEMS Microbiol. Ecol. 43, 1-11. DOI:10.1016/S01686496(02)00449-X.

Hiraishi A., Shin Y.K., Sugiyama J., 1997. Proposal to reclassify Zoogloea ramigera IAM 12670 (P. R. Dugan 115) as Duganella zoogloeoides gen. nov., sp. nov. Int. J. Syst. Bacteriol. 47, 1249-1252. DOI:10.1099/00207713-47-4-1249.

Huelsenbeck, J.P., Ronquist, F., 2001. MRBAYES: Bayesian inference of phylogenetic trees. Bioinformatics 17, 754-755. DOI:10.1093/bioinformatics/17.8.754.

Inderjit, Evans, H., Crocoll, C., Bajpai, D., Kaur, R., Feng, Y.L., Silva, C., Carreón, J.T., A Valientebanuet, A., Gershenzon, J., Callaway, R.M., 2011. Volatile chemicals from leaf litter are associated with invasiveness of a Neotropical weed in Asia. Ecol. 92, 316-324. DOI: $10.1890 / 10-0400.1$.

Jones, D.L., Nguyen, C., Finlay, R.D., 2009. Carbon flow in the rhizosphere: Carbon trading at the soil-root interface. Plant Soil 321, 5-33. DOI:10.1007/s11104-009-9925-0.

Kanu, S.A., Dakora, F.D., 2012. Symbiotic nitrogen contribution and biodiversity of root-nodule 
531

532

533

534

535

536

537

538

539

540

541

542

543

544

545

546

547

548

549

550

551

552

553

554

555

556

557

558

559

560

561

562

563

564

565

566

bacteria nodulating Psoralea species in the Cape Fynbos, South Africa. Soil Biol. Biochem. 54, 68-76. DOI:10.1016/j.soilbio.2012.05.017.

Khare, E., Arora, N.K., 2010. Effect of indole-3-acetic acid (IAA) produced by Pseudomonas aeruginosa in suppression of charcoal rot disease of Chickpea. Curr. Microbiol. 61, 64-68. DOI:10.1007/s00284-009-9577-6.

Kuklinsky-Sobral, J., Araújo, W.L., Mendes, R., Geraldi, I.O., Pizzirani-Kleiner, A.A., Azevedo, J.L., 2004. Isolation and characterization of soybean-associated bacteria and their potential for plant growth promotion. Environ. Microbiol. 6, 1244-1251. DOI:10.1111/j.14622920.2004.00658.x.

Lafay, B., Burdon, J.J., 2006. Molecular diversity of rhizobia nodulating the invasive legume Cytisus scoparius in Australia. J. Appl. Microbiol. 100, 1228-1238. DOI:10.1111/j.13652672.2006.02902.x.

Lehan, N.E., Murphy, J.R., Thorburn, L.P., Bradley, B.A., 2013. Accidental introductions are an important source of invasive plants in the continental United States. Am. J. Bot. 100, $1287-$ 1293. DOI:10.3732/ajb.1300061.

Li, L., Sinkko, H., Montonen, L., Wei, G., Lindström, K., Räsänen, L.A., 2012. Biogeography of symbiotic and other endophytic bacteria isolated from medicinal Glycyrrhiza species in China. FEMS Microbiol. Ecol. 79, 46-68. DOI:10.1111/j.1574-6941.2011.01198.x.

Li, W.J., Zhang, Y.Q., Park, D.J., Li, C.T., Xu, L.H., Kim, C.J., Jiang, C.L., 2004. Duganella violaceinigra sp. nov., a novel mesophilic bacterium isolated from forest soil. Int. J. Syst. Evol. Microbiol. 54, 1811-1814. DOI:10.1099/ijs.0.63141-0.

Liao, C., Peng, R., Luo, Y., Zhou, X., Wu, X., Fang, C., Chen, J., Li, B., 2008. Altered ecosystem carbon and nitrogen cycles by plant invasion: A meta-analysis. New Phytol. 177, 706-714. DOI:10.1111/j.1469-8137.2007.02290.x.

Loaces, I., Ferrando, L., Scavino, A.F., 2011. Dynamics , diversity and function of endophytic siderophore-producing bacteria in rice. Microb. Ecol. 61, 606-618. DOI:10.1007/s00248010-9780-9.

Lodewyckx, C., Vangronsveld, J., Porteous, F., Moore, E.R.B., Taghavi, S., Mezgeay, M., Van der Lelie, D., 2002. Endophytic bacteria and their potential applications. Crit. Rev. Plant Sci. 21, 583-606. DOI:10.1080/0735-260291044377.

Loper, J.E., Schrot. M.N., 1986. Influence of bacterial sources of indole-3-acetic acid on root elongation of Sugar Beet. Phytopathology. DOI:10.1094/Phyto-76-386.

Machuca, A., Milagres, A.M.F., 2003. Use of CAS-agar plate modified to study the effect of different variables on the siderophore production by Aspergillus. Lett. Appl. Microbiol. 36, 177-181. DOI:10.1046/j.1472-765X.2003.01290.x.

Magnani, G.S., Didonet, C.M., Cruz, L.M., Picheth, C.F., Pedrosa, F.O., Souza, E.M., 2010. 
567

568

569

570

571

572

573

574

575

576

577

578

579

580

581

582

583

584

585

586

587

588

589

590

591

592

593

594

595

596

597

598

599

600

601

602

Diversity of endophytic bacteria in Brazilian sugarcane. Genet. Mol. Res. 9, 250-258. DOI:10.4238/vol9-1gmr703.

Miki, T., Yokokawa, T., Matsui, K., 2014. Biodiversity and multifunctionality in a microbial community: a novel theoretical approach to quantify functional redundancy. Proc. R. Soc. B Biol. Sci. 281, 20132498. DOI:10.1098/rspb.2013.2498.

Moles, A.T., Gruber, M.A.M., Bonser, S.P., 2008. A new framework for predicting invasive plant species. J. Ecol. 96, 13-17. DOI:10.1111/j.1365-2745.2007.01332.x.

Moseman, S.M., Zhang, R., Qian, P.Y., Levin, L.A., 2009. Diversity and functional responses of nitrogen-fixing microbes to three wetland invasions. Biol. Invasions 11, 225-239. DOI:10.1007/s10530-008-9227-0.

Niu, H.B., Liu, W.X., Wan, F.H., Liu, B., 2007. An invasive aster (Ageratina adenophora) invades and dominates forest understories in China: altered soil microbial communities facilitate the invader and inhibit natives. Plant Soil 294, 73-85. DOI:10.1007/s11104-0079230-8.

Olivares, F.L., Baldani, V.L.D., Reis, V.M., Baldani, J.I., Döbereiner, J., 1996. Occurrence of the endophytic diazotrophs Herbaspirillum spp. in roots, stems, and leaves, predominantly of Gramineae. Biol Fertil Soils 21, 197-200. DOI:10.1007/BF00335935.

Park, M., Kim, C., Yang, J., Lee, H., Shin, W., Kim, S., Sa, T., 2005. Isolation and characterization of diazotrophic growth promoting bacteria from rhizosphere of agricultural crops of Korea. Microbiol. Res. 160, 127-133. DOI:10.1016/j.micres.2004.10.003.

Parker, M.A., Malek, W., Parker, I.M., 2006. Growth of an invasive legume is symbiont limited in newly occupied habitats. Divers. Distrib. 12, 563-571. DOI:10.1111/j.13669516.2006.00255.x.

Pastor, N., Rosas, S., Luna, V., Rovera, M., 2014. Inoculation with Pseudomonas putida PCI2, a phosphate solubilizing rhizobacterium, stimulates the growth of tomato plants. Symbiosis 62, 157-167. DOI:10.1007/s13199-014-0281-3.

Rambaut A, 2016. FigTree v1.3.1. http://tree.bio.ed.ac.uk/software/figtree/ (Accessed 4 October 2016).

Rodríguez-Echeverría, S., Crisóstomo, J.A., Freitas, H., 2007. Genetic diversity of rhizobia associated with Acacia longifolia in two stages of invasion of coastal sand dunes. Appl. Environ. Microbiol. 73, 5066-5070. DOI:10.1128/AEM.00613-07.

Rodríguez-Echeverría, S., Traveset, A., 2015. Putative linkages between below- and aboveground mutualisms during alien plant invasions. AoB Plants 7. DOI:10.1093/aobpla/plv062.

Rout, M.E., Callaway, R.M., 2009. An invasive plant paradox. Science. 324, 734-735. DOI:10.1126/science.1173651. 
603

604

605

606

607

608

609

610

611

612

613

614

615

616

617

618

619

620

621

622

623

624

625

626

627

628

629

630

631

632

633

634

635

636

637

638

Rout, M.E., Chrzanowski, T.H., 2009. The invasive Sorghum halepense harbors endophytic $\mathrm{N}_{2}-$ fixing bacteria and alters soil biogeochemistry. Plant Soil 315, 163-172. DOI:10.1007/s11104-008-9740-z.

Rout, M.E., Chrzanowski, T.H., Westlie, T.K., Deluca, T.H., Callaway, R.M., Holben, W.E., 2013. Bacterial endophytes enhance competition by invasive plants. Am J Bot 100, 17261737. DOI:10.3732/ajb.1200577.

Santi, C., Bogusz, D., Franche, C., 2013. Biological nitrogen fixation in non-legume plants. Ann. Bot. 111, 743-767. DOI:10.1093/aob/mct048.

Schloss, P.D., Westcott, S.L., Ryabin, T., Hall, J.R., Hartmann, M., Hollister, E.B., Lesniewski, R.A., Oakley, B.B., Parks, D.H., Robinson, C.J., Sahl, J.W., Stres, B., Thallinger, G.G., Van Horn, D.J., Weber, C.F., 2009. Introducing mothur: open-source, platform-independent, community-supported software for describing and comparing microbial communities. Appl. Environ. Microbiol. 75, 7537-7541. DOI:10.1128/AEM.01541-09.

Schwyn, B., Neilands, J.B., 1987. Universal chemical assay for the detection and determination of siderophore. Anal. Biochem. 160, 47-56. DOI:10.1016/0003-2697(87)90612-9.

Siemann, E., Rogers, W.E., 2003. Changes in light and nitrogen availability under pioneer trees may indirectly facilitate tree invasion of grasslands. J. Ecol. 91, 923-931. DOI:10.1046/j.1365-2745.2003.00822.x.

Silva, K. da, Nóbrega, R.S.A., Lima, A.S., Barberi, A., Moreira, F.M. de S., 2011. Density and diversity of diazotrophic bacteria isolated from Amazonian soils using $\mathrm{N}$-free semi-solid media. Sci. Agric. 68, 518-525. DOI:10.1590/S0103-90162011000500002.

Silvestro, D., Michalak, I., 2012. RaxmlGUI: A graphical front-end for RAxML. Org. Divers. Evol. 12, 335-337. DOI:10.1007/s13127-011-0056-0.

Sylvester-Bradley, R., Asakawa, N., La Torraca, S., Magalhães, F.M.M., Oliveira, L.A., Pereira, R.M., 1982. Levantamento quantitativo de microrganismos solubilizadores de fosfatos na rizosfera de gramíneas e leguminosas forrageiras na Amazônia. Acta Amaz. 12, 15-22. http://dx.doi.org/10.1590/1809-43921982121015.

Thompson, J.D., Gibson, T.J., Plewniak, F., Jeanmougin, F., Higgins, D.G., 1997. The CLUSTAL_X windows interface: flexible strategies for multiple sequence alignment aided by quality analysis tools. Nucleic Acids Res. 25, 4876-4882. DOI:10.1093/nar/25.24.4876.

Torres-Cortés, G., Bonneau, S., Bouchez, O., Genthon, C., Briand, M., Jacques, M.A., Barret, M., 2018. Functional microbial features driving community assembly during seed germination and emergence. Front. Plant Sci. 9, 1-16. DOI:10.3389/fpls.2018.00902.

Van der Putten, W.H., Bardgett, R.D., Bever, J.D., Bezemer, T.M., Casper, B.B., Fukami, T., Kardol, P., Klironomos, J.N., Kulmatiski, A., Schweitzer, J.A., Suding, K.N., Van de Voorde, T.F.J., Wardle, D.A., 2013. Plant-soil feedbacks: the past, the present and future 
639

640 challenges. J. Ecol. 101, 265-276. DOI:10.1111/1365-2745.12054.

Van der Putten, W.H., Klironomos, J.N., Wardle, D.A., 2007. Microbial ecology of biological invasions. ISME J. 1, 28-37. DOI:10.1038/ismej.2007.9.

Walther, G.R., Post, E., Convey, P., Menzel, A., Parmesan, C., Beebee, T.J.C., Fromentin, J.M., Hoegh-Guldberg, O., Bairlein, F., 2002. Ecological responses to recent climate change. Nature 416, 389-395. DOI:10.1038/416389a.

Wang, M.L., Feng, Y.L., 2005. Effects of soil nitrogen levels on morphology, biomass allocation and photosynthesis in Ageratina adenophora and Chromoleana odorata. Acta Phytoecol. Sin. 29, 697-705. DOI:10.17521/cjpe.2005.0093.

Wang, R., Wang, Y.Z., 2006. Invasion dynamics and potential spread of the invasive alien plant species Ageratina adenophora (Asteraceae) in China. Divers. Distrib. 12, 397-408. DOI:10.1111/j.1366-9516.2006.00250.x

Wei, G., Chen, W., Zhu, W., Chen, C., Young, J.P.W., Bontemps, C., 2009. Invasive Robinia pseudoacacia in China is nodulated by Mesorhizobium and Sinorhizobium species that share similar nodulation genes with native American symbionts. FEMS Microbiol. Ecol. 68, 320328. DOI:10.1111/j.1574-6941.2009.00673.x.

Williamson, G. B., Richardson, D., 1988. Bioassays for allelopathy: Measuring treatment responses with independent controls. J. Chem. Ecol. 14, 181-187. DOI:10.1007/BF01022540.

Wilsey, B.J., Wayne Polley, H., 2006. Aboveground productivity and root-shoot allocation differ between native and introduced grass species. Oecologia 150, 300-309. DOI:10.1007/s00442-006-0515-z.

Xu, C.W., Yang, M.Z., Chen, Y.J., Chen, L.M., Zhang, D.Z., Mei, L., Shi, Y.T., Zhang, H.B., 2012. Changes in non-symbiotic nitrogen-fixing bacteria inhabiting rhizosphere soils of an invasive plant Ageratina adenophora. Appl. Soil Ecol. 54, 32-38. DOI:10.1016/j.apsoil.2011.10.021.

Zawoznik, M.S., Vázquez, S.C., Herrera, S.M.D., Groppa, M.D., 2014. Search for endophytic diazotrophs in barley seeds. Brazilian J. Microbiol. 45, 621-625. DOI:10.1590/S151783822014000200033.

Zhao L., Meng L., Li, B.P., 2007. Effects of fertilization on the relative competitive ability of Eupatorium adenophorum and Lolium perenne at their seedling stage. Chinese J. Ecol. 26, 1743-1747. DOI:10.13292/j.1000-4890.2007.0303. 
Figure 1 (on next page)

Phylogenetic tree of representative potential reNFB OTU of $A$. adenophora and their best blast matches showing their phylogenetic affinities.

The bootstrap values and posterior probability are indicated at the branch node, shown as MrBayes/maximum likelihood. Each OTU and its occurrence time in XM (solid circle), CY (open circle), XS (solid square), WS (open square) and YL (solid triangle) regions is indicated in parentheses, as well as the GenBank accession numbers of reference sequences. The scale bar represents $6 \%$ estimated sequence divergence. Flavobacterium johnsoniae (NR_074455.1) was used as the out-group. 
Figure 2 (on next page)

The species composition at the genus level $(A)$ and the Shannon diversity index at the $97 \%$ identity level (B) of $A$. adenophora reNFB from different study regions.

Error bars depict the standard error. Black dots show the values of the Shannon diversity index. One-way ANOVA was used to compare Shannon diversity indices across different study regions $(F=8.628, P=0.003)$, and the homogeneity test of variance was passed $(P=$ 0.412), and Duncan's multiple range test was used for pairwise comparison. Different lowercase letters indicate that the difference was significant, and identical lowercase letters indicate nonsignificant differences. 
A

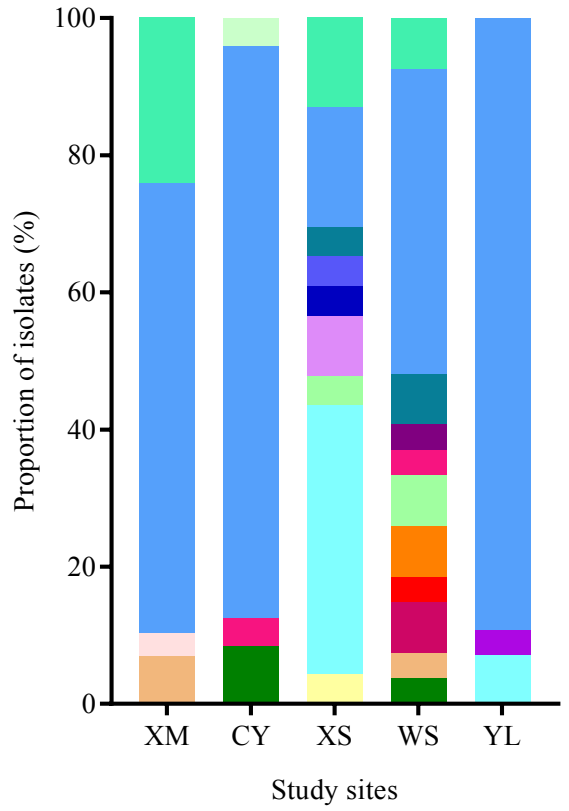

B

Variovorax

Rhizobium

- Pseudarthrobacter

- Phyllobacterium

- Paracoccus

Pseudomonas

Paraburkholderia

- Pantoea

- Paenibacillus

Nocardioides

Neorhizobium

Mitsuaria

Lysobacter

Duganella

Burkholderia Brachybacterium

Bosea

- Bacillus

Agrobacterium

$\stackrel{0}{2}$

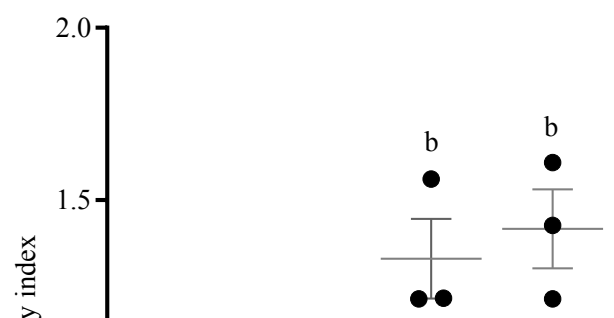

a

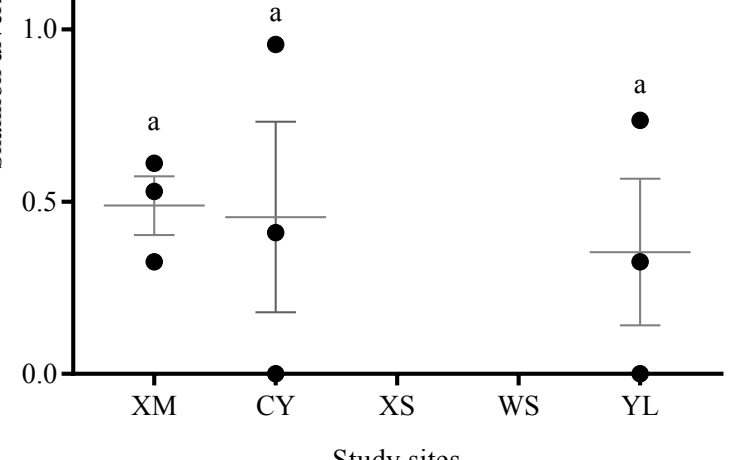




\section{Figure 3 (on next page)}

IAA accumulation (A, B), phosphorus solubility index (C) and siderophore units (D) of the total reNFB from each study region. Differences in IAA accumulation ( $E, F)$, soluble phosphorus index $(\mathrm{G})$ and siderophore units $(\mathrm{H})$ among the three dominant genera.

The colorful points represent the values of growth-promoting products of each isolate. The horizontal lines in figures $A, B, C$ and $D$ indicate the median number of each study region. The horizontal lines and whiskers in figure $\mathrm{E}, \mathrm{F}, \mathrm{G}$ and $\mathrm{H}$ represent the mean value and $\mathrm{min}$ to max values, respectively. A nonparametric test was used to compare the production capacity of growth-promoting products between sampling areas. Log-transformations were applied to IAA accumulation and the phosphorus solubility index in figure $E, F$ and $G$, while square-root transformations were applied to siderophore units in figure $\mathrm{H}$. 

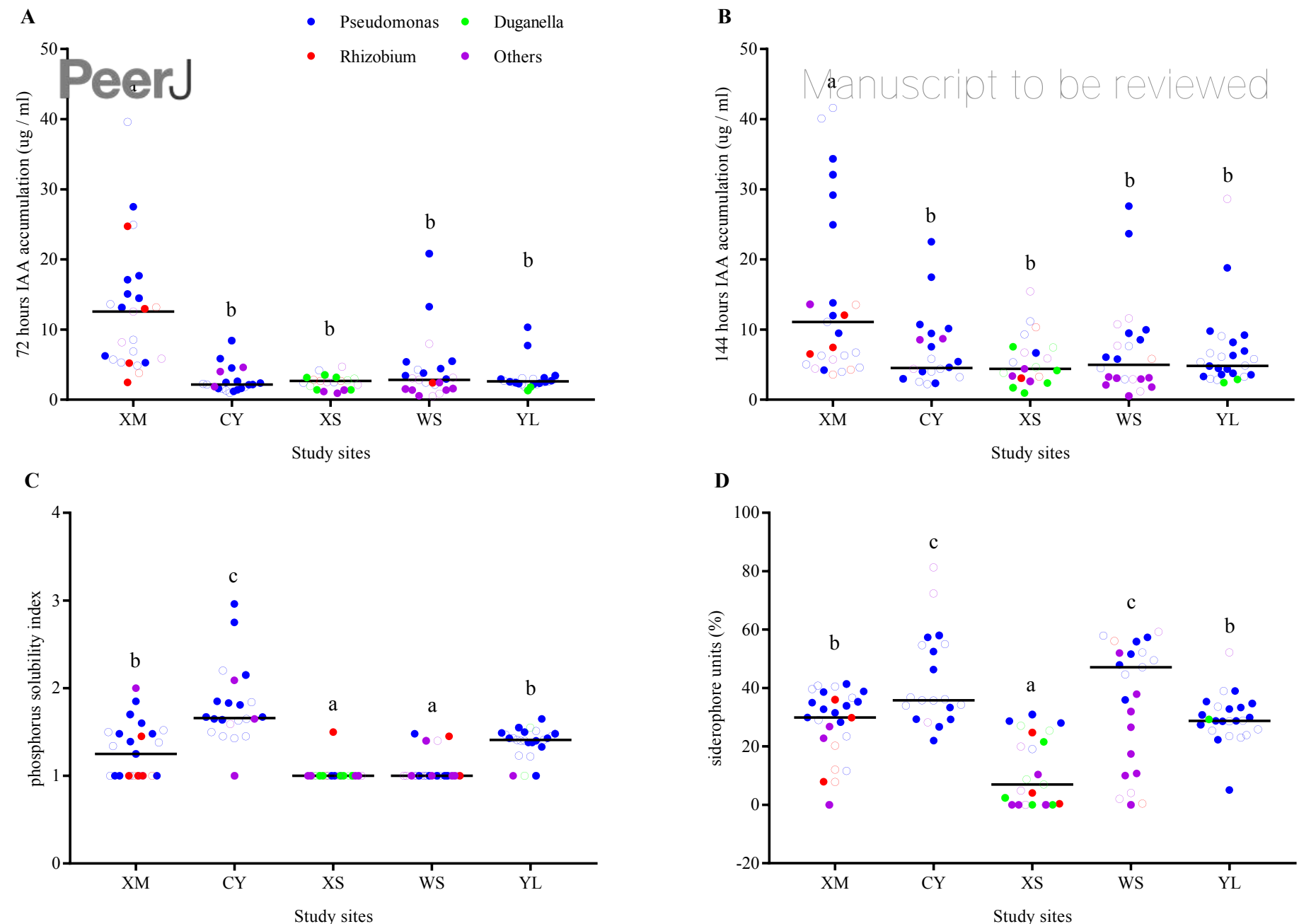

D



F
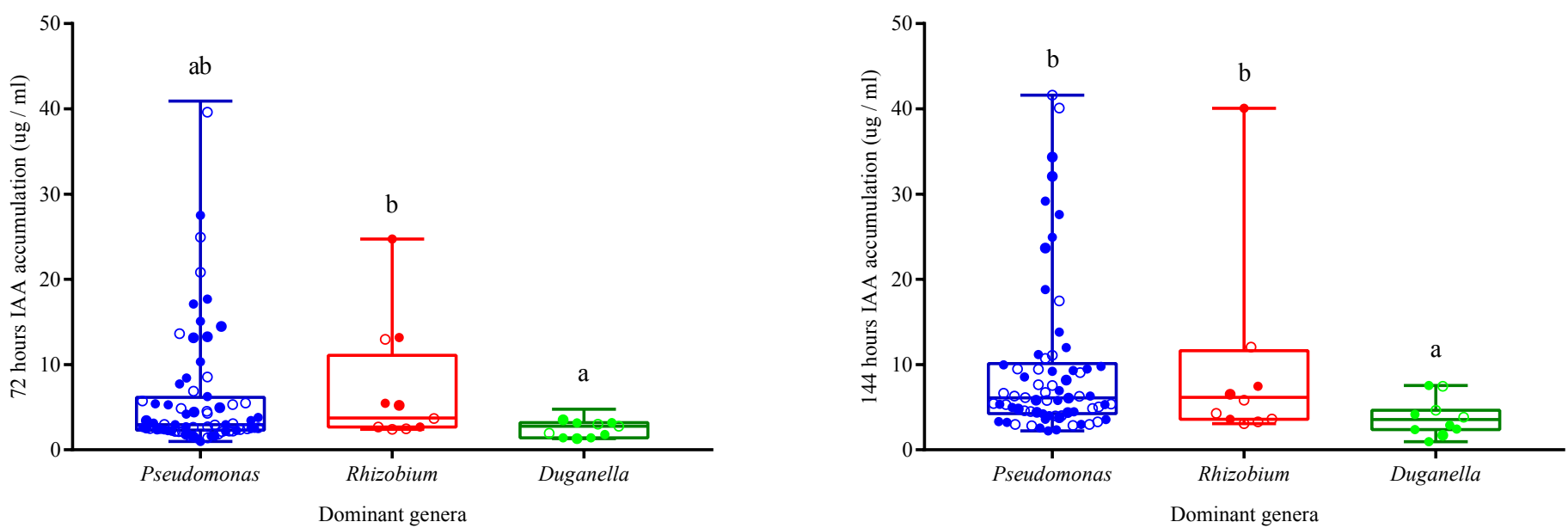

G

H

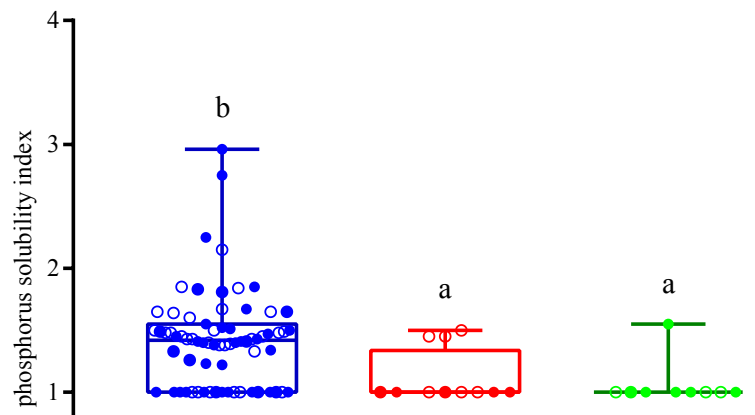

Peer] reviewing PDF | (2018:12:33237:2:0:NEW 24 Apr 2019)

Pseudomonas

Rhizobium

Duganella

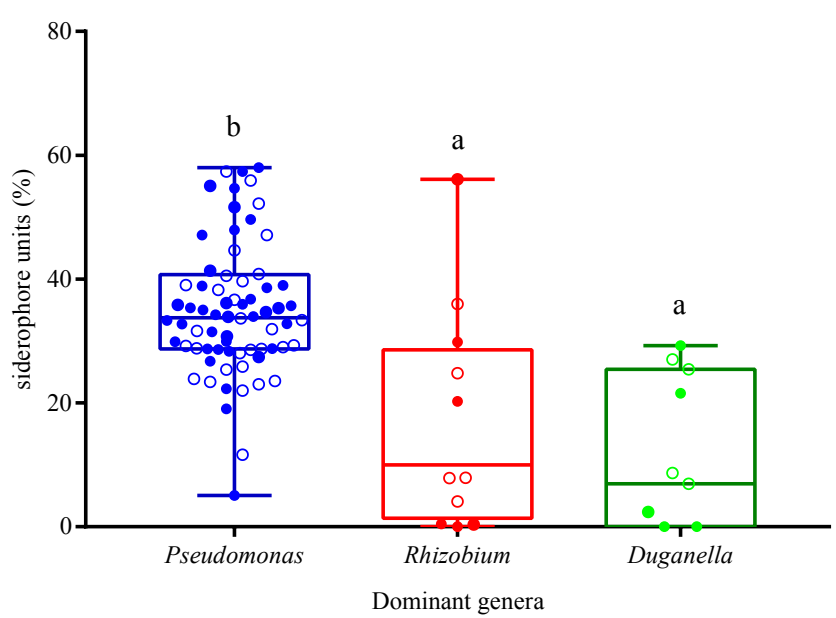




\section{Figure 4 (on next page)}

Linear regression analysis between the Shannon diversity index of each $A$. adenophora and their reNFB growth-promoting product productivity.

Log transformations were applied to IAA accumulation and the phosphorus solubility index in figures A, B and C. Square-root transformations were applied to siderophore units in figure D. The equation for the regression of 72 hours IAA accumulation and Shannon diversity index is $Y=-0.1367 * X+0.6502$ (Fig. A). The equation for the regression of 144 hours IAA accumulation and Shannon diversity index is $Y=-0.1085 * X+0.8565$ (Fig. B). The equation for the regression of phosphorus solubility index and Shannon diversity index is $Y=-0.127 * X$ +0.1979 (Fig. C). The equation for the regression of siderophores units and Shannon diversity index is $Y=-0.08961 * X+0.5673$ (Fig. D). 
PeerJ
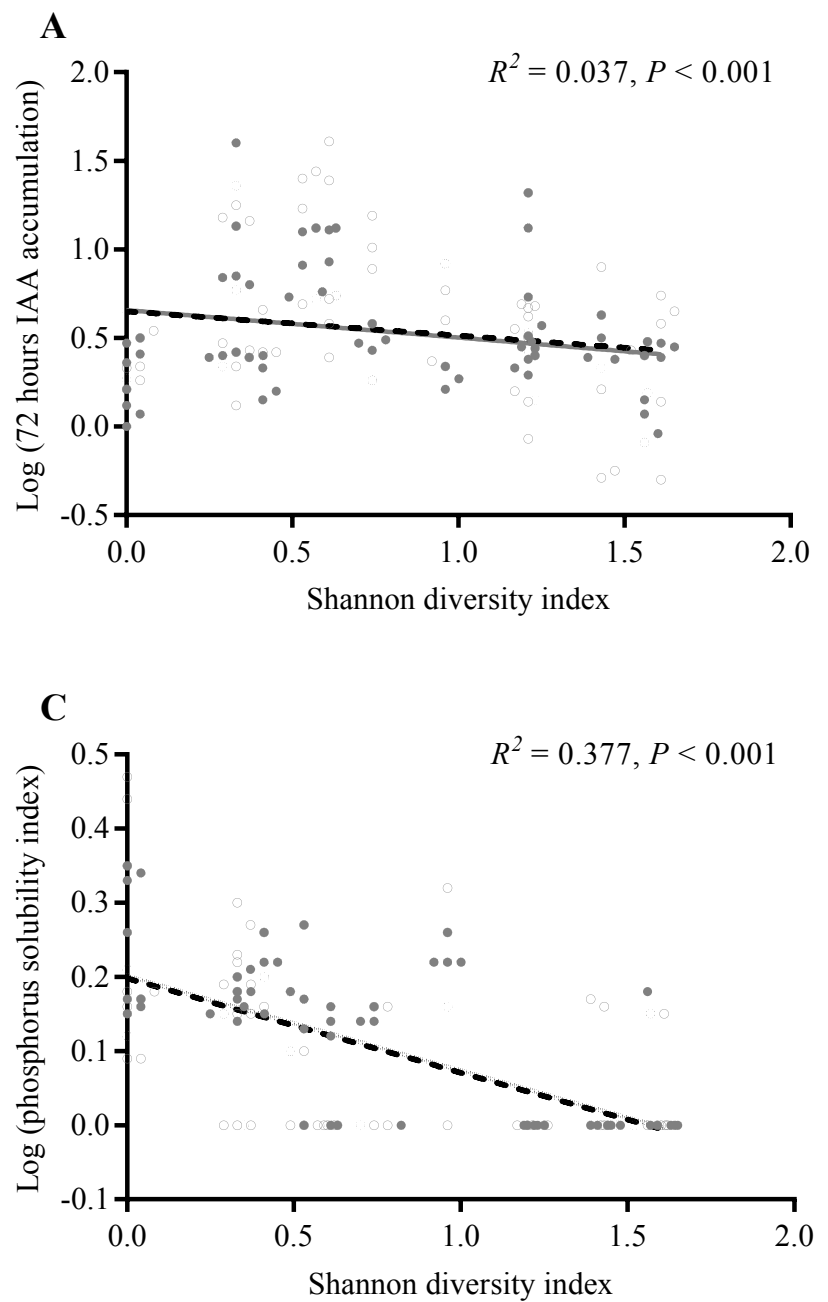

Peer) reviewing PDF | (2018:12:33237:2:0:NEW 24 Apr 2019)

\section{Manuscript to be reviewed}

B

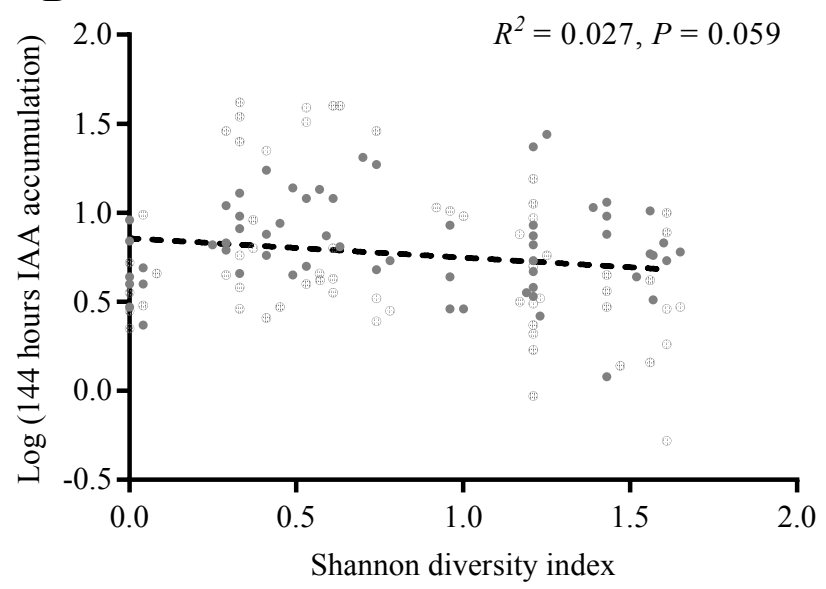

D

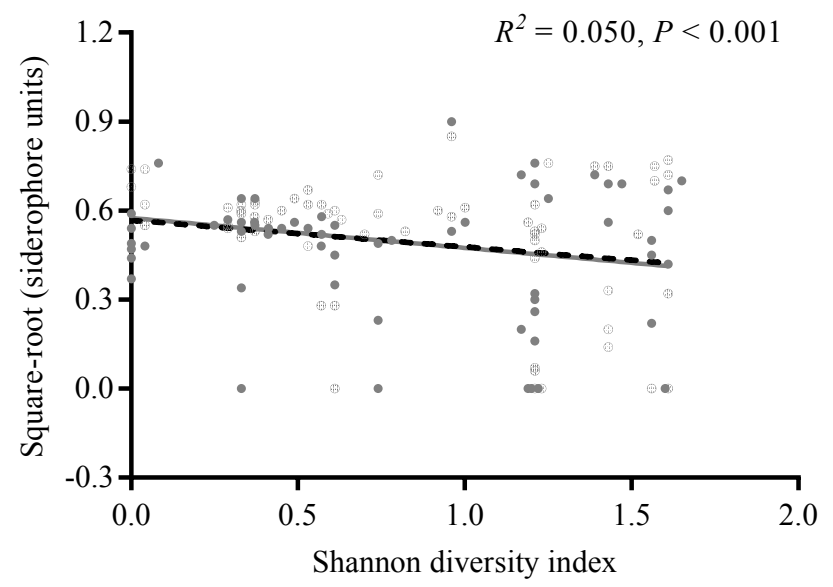


Figure $\mathbf{5}$ (on next page)

Effects of focal reNFB on the growth performance of $A$. adenophora seedlings.

1 represents Pseudomonas sp. (OTU01; WS29); 2 represents Pseudomonas sp. (OUT 01;

WS14); 3 represents Duganella sp. (OTU02; XS01); 4 represents Rhizobium sp. (OTU03;

XM06); 5 represents Rhizobium sp. (OUT11; XM04); 6 represents Rhizobium sp. (OTU17;

WS05); and Con. represents sterile water control. Log transformations were applied to wet

and dry biomass (C, D, E, F). Significant difference is the comparison between treatment and control by using Independent-Samples $T$ test and marked as following $(*<0.050, * *<0.010$, $* * *<0.001)$. Error bars depict the standard error for the average growth performances of $A$. adenophora. 




\section{Figure 6 (on next page)}

Response indices (RI) of shoot and root lengths of wet and dry biomass of $A$. adenophora seedlings.

Significant difference is the comparison between shoot and root by using Nonparametric tests $\left(P_{\text {length }}=0.521, P_{\text {wet-biomass }}=0.037, P_{\text {dry-biomass }}=0.037\right)$ and mark as following (n.s. $>0.05$, $*<0.05)$. The long horizontal lines represent mean value. Error bars depict the standard deviation for the average RI of $A$. adenophora shoot and root, respectively. 


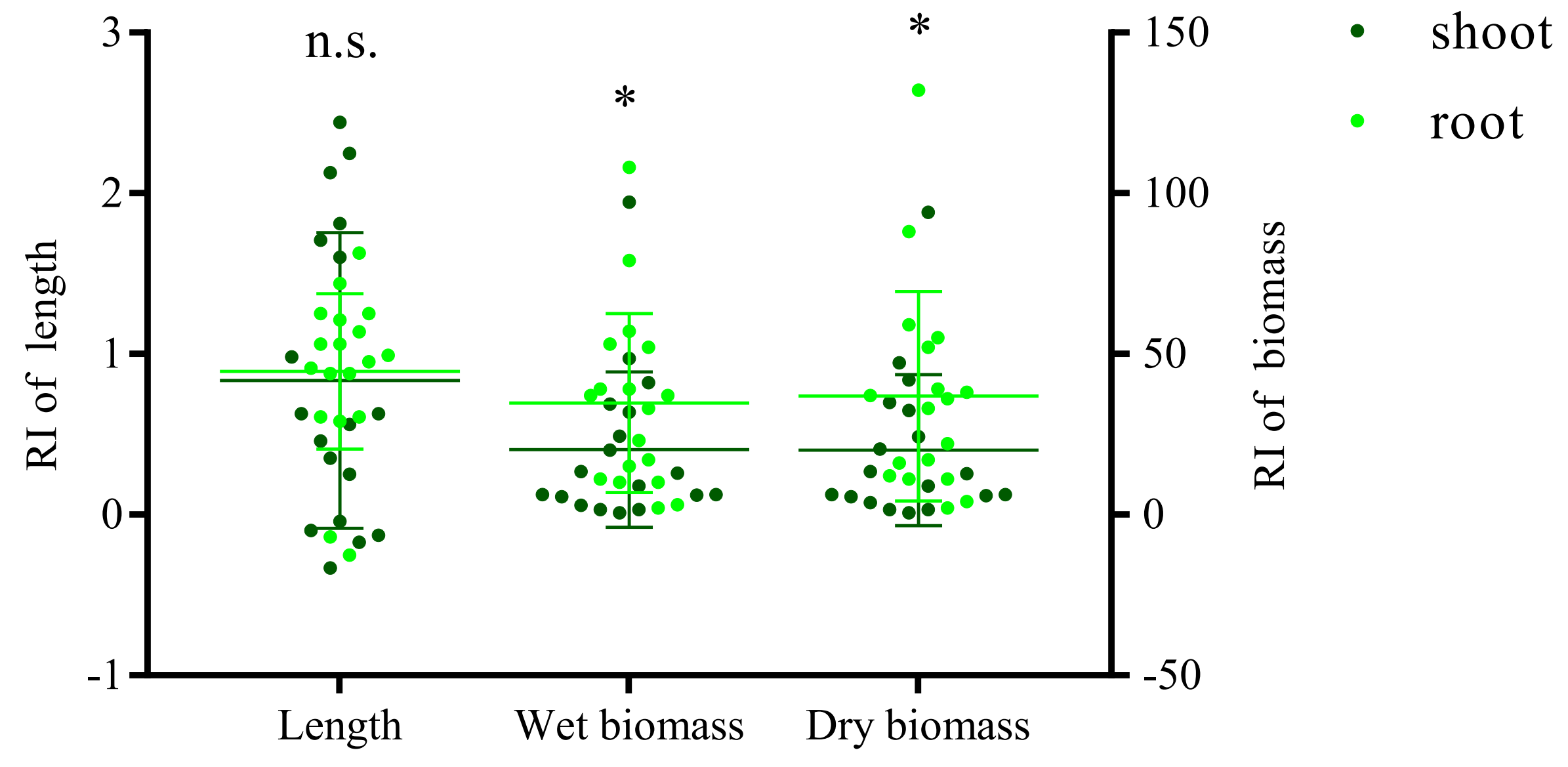




\section{Table $\mathbf{1}$ (on next page)}

Geographical description and vegetation of study regions

a XM, Ximeng county; CY, Cangyuan county; XS located at Kunming city; WS, Wenshan Zhuang and Miao Autonomous Prefecture; YL, Yunlong county. 
1

\begin{tabular}{|c|c|c|c|c|}
\hline Region $^{\text {a }}$ & Altitude (m) & Latitude & Longitude & Dominant plants \\
\hline $\mathrm{XM}$ & 1715 & 99.80 & 22.62 & Sida acuta, Urena lobata, Rubus corchorifolius \\
\hline CY & 1708 & 99.30 & 23.22 & $\begin{array}{l}\text { Rubus corchorifolius, Betula alnoides, Pistacia weinmannifolia, } \\
\text { Desmodium sequax }\end{array}$ \\
\hline $\mathrm{XS}$ & 2040 & 102.37 & 24.50 & $\begin{array}{l}\text { Pinus yunnanensis Franch, Alnus nepalensis, Myrica rubra, } \\
\text { Amphicarpaea edgeworthii }\end{array}$ \\
\hline WS & 1980 & 104.17 & $24.52^{\prime}$ & Desmodium sequax \\
\hline YL & 2128 & 99.43 & 25.87 & Pinus yunnanensis Franch, Desmodium heterocarpon \\
\hline
\end{tabular}

2 